$$
\text { بمس الله الرحمن الرحيم }
$$

\title{
كلمة التصرير
}

\section{Editorial Words}

\section{Kata Pengantar}

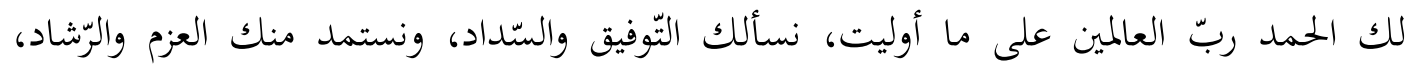

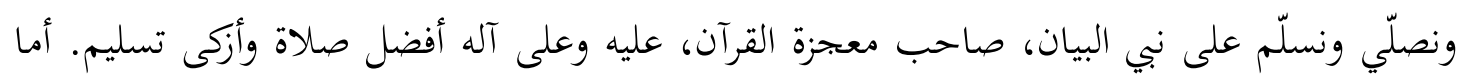

فإن كل خطوة تخطوها بحلّة الدّراسات اللّغوية والأدبيّة بتعل البون بينها وبين سابقتها شاسعا؛ ذلك

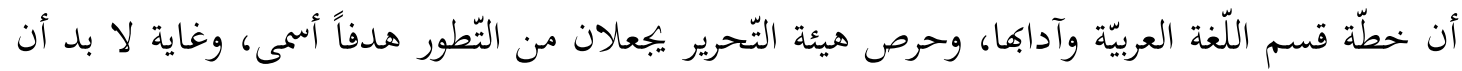

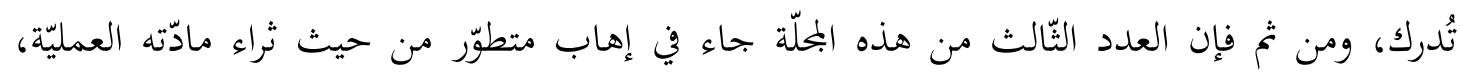

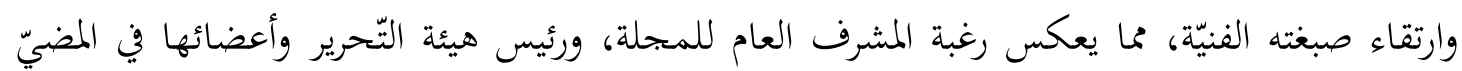
قدماً خو فضاءات أرحب، ومسارات أغنى بأفنان العلم والمعرفة الوارفة.

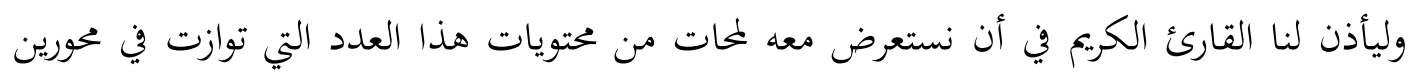

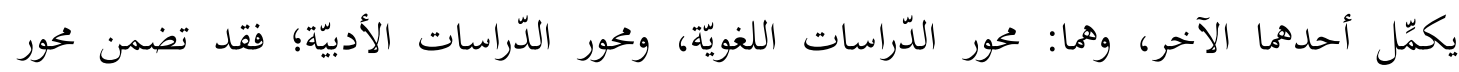

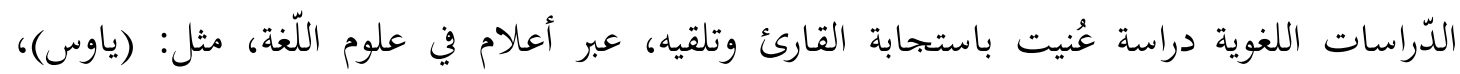

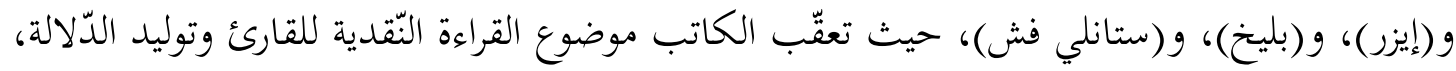

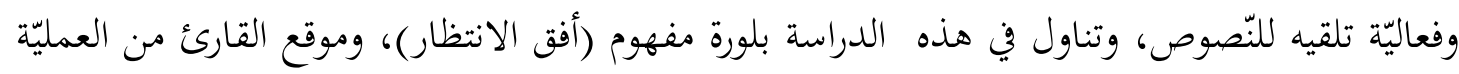

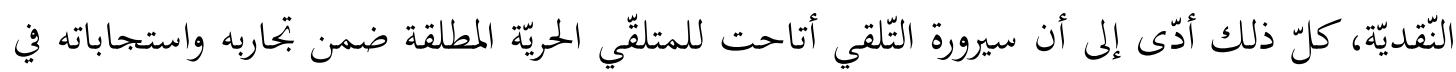
تشكيل النّص الأدبي.

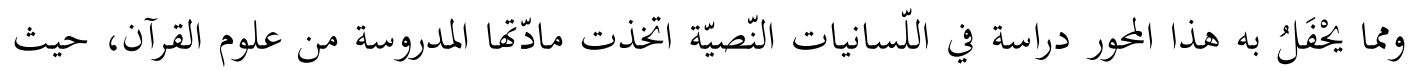

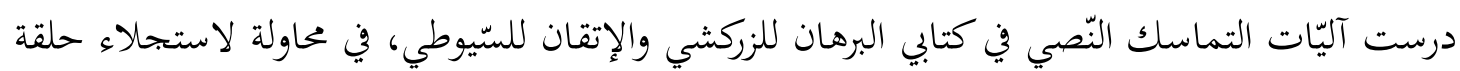

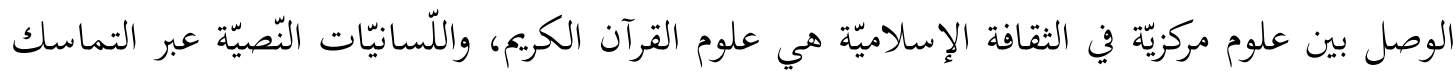

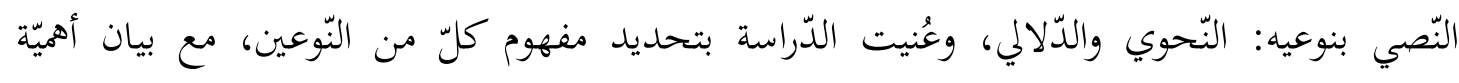

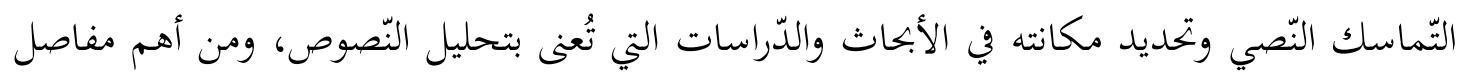

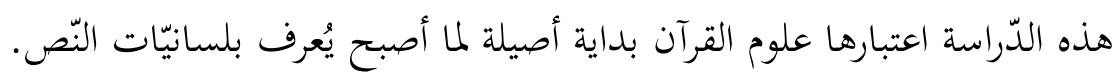


كما اشتمل المحور اللغوي على دراسة انصبت على استراتيجيّات تعلّم مهارة الكلام لدى الدّارسين

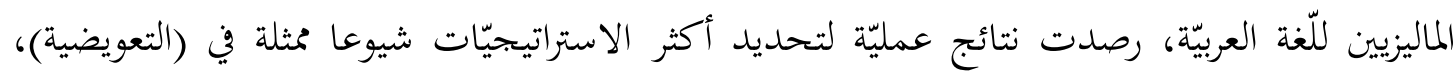
و (التذكريّة)، و (المعرفية)، عبر استبانة محكمة البناء أوصلت الدّارسين إلى نتائج عالية الصّدقيّة.

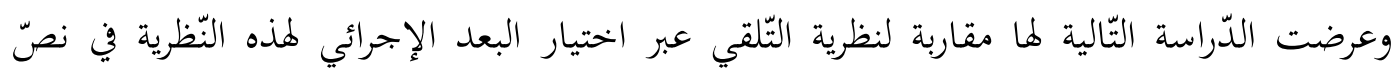

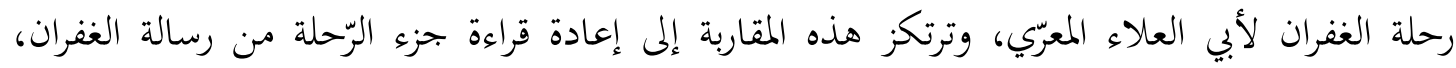

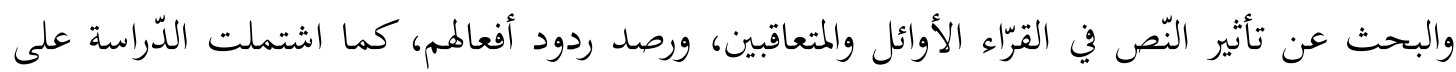

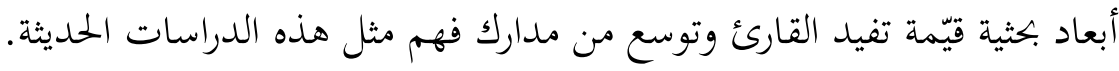

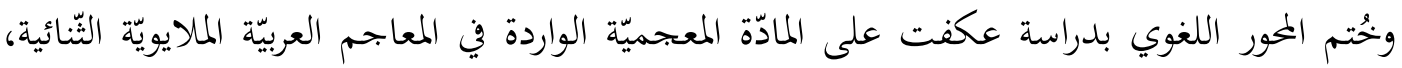

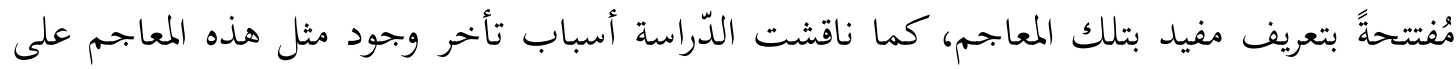

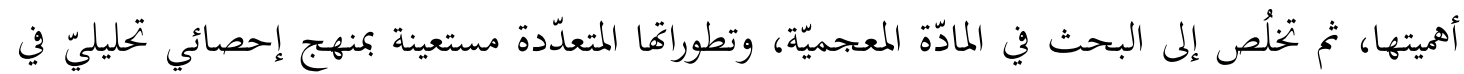
مضمار الدّراسات العلميّة الموثوقة. ولا نكاد -في المخور الثّاني - نتفيّأ ظلال دوحة الأدب حتى تطالعنا دراسة في غاية الأهميّة، تتناول

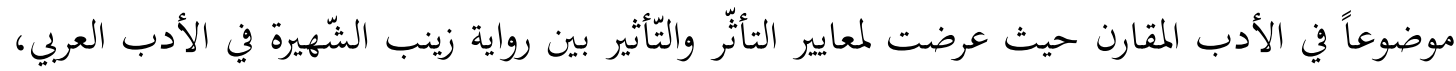

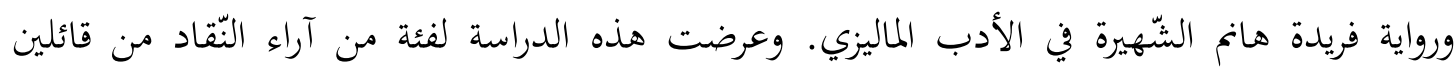

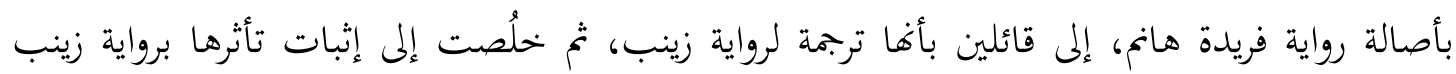

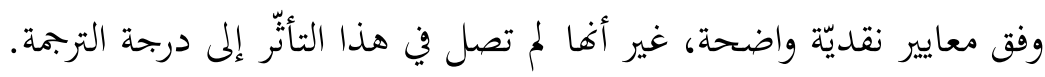

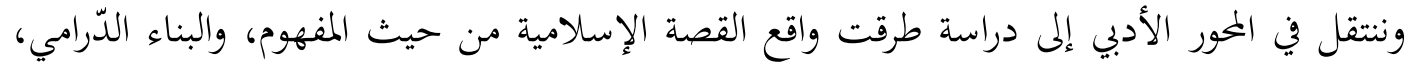

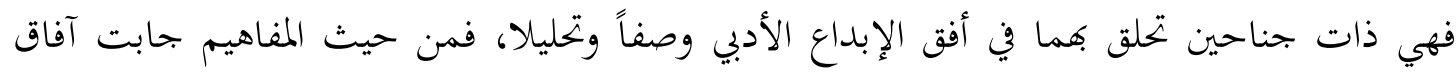

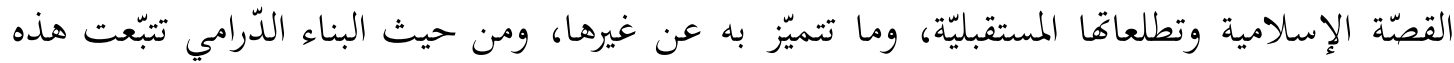

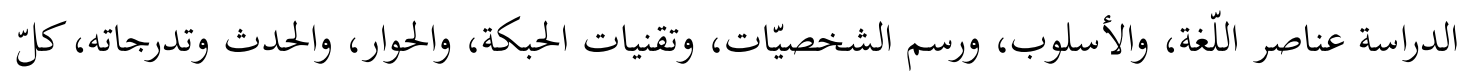

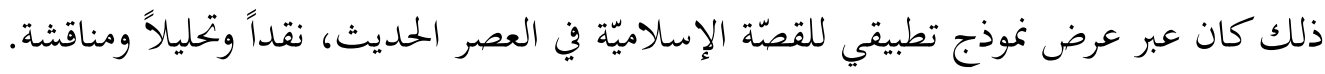

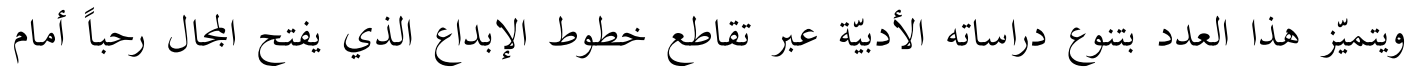

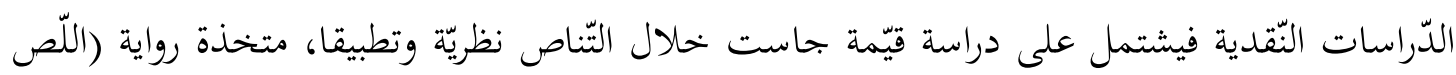

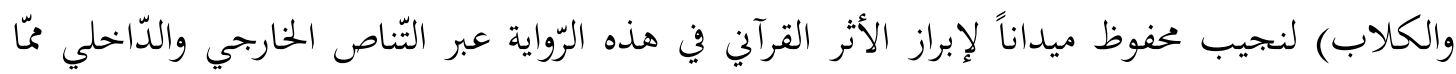

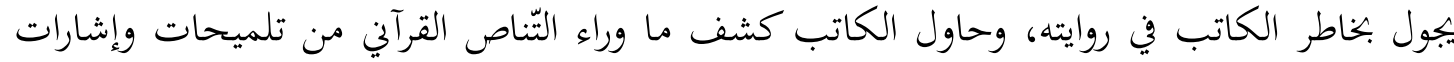

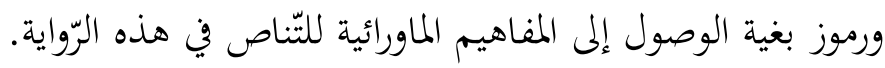

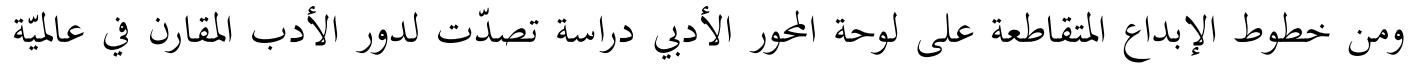

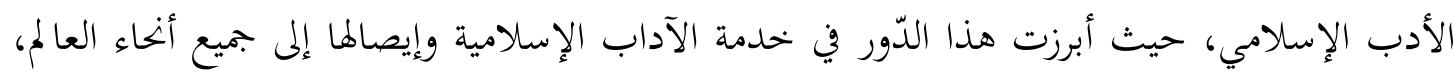

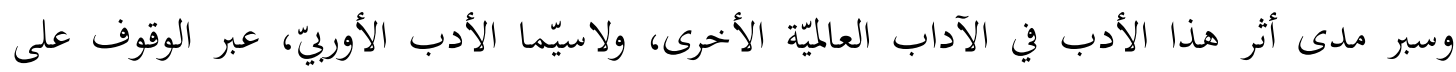

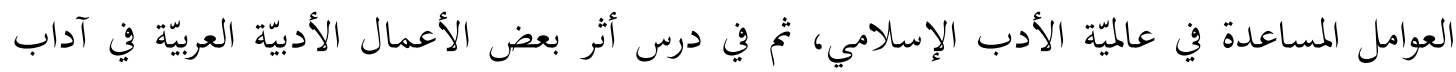


الأمم الأخرى، كقصة بحنون ليلى، وقصة حي بن يقظان، وكتاب ألف ليلة وليلة، وكليلة ودمنة، وأثر الأدب الإسلامي في الكوميديا الإلهيّة لدانتي.

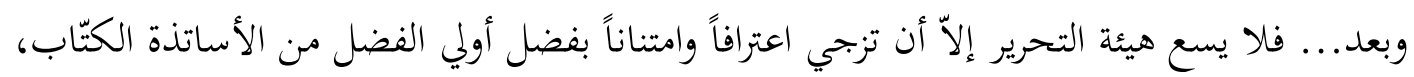

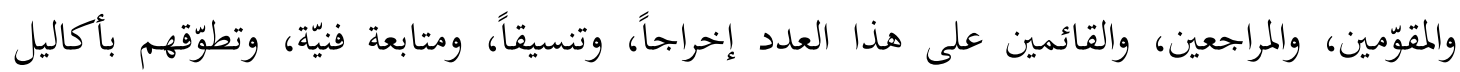

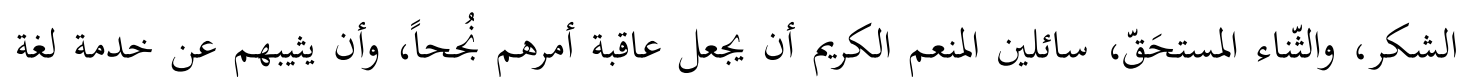

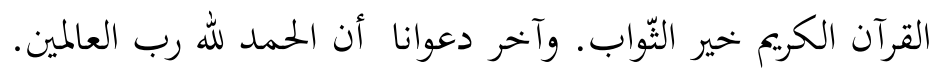

